\title{
Free to learn: why unleashing the instinct to play will make our children happier, more self-reliant, and better students for life
}

\author{
Aditi Pai (1)
}

\author{
Book details \\ Peter Gray. New York: Basic Books, 2013. Pp xii-273. H/b \$27.99
}

Peter Gray's "Free to learn" is a powerful and interesting exploration of "the biological underpinnings of education." Inspired by his own young son's rebellion against schooling, here he sets out to prove that schools destroy the natural instinct to learn. Whether one agrees with him on the evils of the present education system or vigorously disagrees that the current system fails our students utterly on every level, this is a thought-provoking read for not only evolutionary biologists, but also psychologists, citizens, policy-makers, and especially for parents and teachers.

Evolutionary developmental psychologist Gray's perspective is that the freedom to play is of utmost significance in promoting learning in children. Autonomy to direct one's time and energy without interference, input or judgement from adults is critical to children's learning. In fact, learning via play, is the only way consistent with human evolutionary history as hunter-gatherers, because play is the means by which children learn to "make friends, overcome fears, solve problems and take control of their lives." Therefore, children suffer irrevocable damage to their mental growth, emotional development, and overall sense of well-being when they are denied the chance at free play.

Children in hunter-gatherer societies learn the skills they need for their life through unstructured time, in which they engage in play guided by their own will and

\footnotetext{
*Correspondence: apai@spelman.edu

Spelman College, 350 Spelman Ln, 30314 Atlanta, Georgia
}

curiosity (Chapter 2). Their play involves storytelling, mimicking adult activities, and shadowing adults, in mixed-age groups without adult interference. A childhood of unstructured play leads to adequate mastery of skills for hunting and gathering in men and women. Thus, the education that occurs in hunter-gather societies occurs in a non-competitive, cooperative, and trustful environment where children are allowed to be autonomous, similar to what humans experienced in much of our evolutionary history.

The advent of agriculture in human history began the shift from the hunter-gatherer to industrialized world's model of education (Chapter 3). The reliance on agriculture emphasized a need for labor and obedience in contrast to the hunter-gatherer's stress on skills and curiosity; thus, agricultural societies devalued play. Children came to be seen as objects to "be raised" or to be "trained" much like crops or livestock rather than independent beings. The modern system of education began to take shape in the 1800s when many societies in Europe and North America adapted compulsory education and was strongly influenced by the Protestant view of schools as "correctional institutions" (p. 68).

Consequently, in sharp contrast to hunter-gatherer education, traditional schools in industrialized nations are primarily run on adult direction, barely allowing children any unstructured time. Modern education, unlike play centered learning, promotes competition rather than cooperation because of the importance placed on evaluation of performance in and of schools. In the last half 
century, the school year as well as day, have grown longer, recess times have grown shorter, evaluation of performance has become more important-all of which have eroded free play time. Sadly, modern schooling has come to overstress resume' building at the expense of anything and everything else in children's lives. The author states that this is to great detriment of both mental and emotional growth of children. He refers to it as the "terrible irony," that education systems, which are meant to prepare students for their future are "paths to nowhere" ( $\mathrm{p}$. 19).

The first failing of modern schools is the failure to promote mental growth of students and learning. Because they fail to promote curiosity, playfulness, and sociability-the environment is not optimal for learning. Any and every type of play (physical, language, exploratory, constructive, fantasy, social) can lead to effective learning because it is "self-chosen and self-directed" and occurs in an "alert, active and non-threatened state of mind" (p. 152), but school lessons do the opposite by taking away autonomy and adding the stress of competition, and overall ruin children's educative instincts (Chapter 6). He goes as far as to suggest that the main deterrent to learning in traditional schools is in fact teaching, because it inhibits curiosity thereby impeding learning. To promote healthy play, trustful parenting (where parents trust children's autonomy) (Chapter 10) and age mixing (where children of different ages are put together) (Chapter 9) are critical, but traditional schooling discourages both which, are additional shortcomings of present day schools. Thus, Gray passionately makes a strong case for student autonomy when he discusses the "seven deadly sins" of the education system (Chapter 4). He makes a valid pointthat traditional schools deny children the basic rights upon which our civilization is based-the right to have a voice in decision making and the right to have equal opportunities. Further, he finds that the schools are guilty of denying liberty, interfering with development of selfdirection, undermining self-motivation, judging learning, interfering with the development of cooperation, inhibiting critical thinking, and reduction in diversity of skills and knowledge.

The second failure of modern schools is that it impairs emotional development of students. The culture of adult directed education leads to children not taking responsibility for themselves and their lives. The lack of unstructured play time denies children a chance to learn to resolve conflict through negotiation and compromise in play groups. The stress on adult dictated and structured play and activity results in lack of opportunity to develop games and rules from children's own imagination. The lack of autonomy can lead to higher anxiety as children learn to think they have little or no control of their situations (Chapter 1, p. 15). Gray argues that this overall dearth of opportunity to develop social skills leads to emotional problems for children, and attributes the higher rates of suicide, anxiety disorders, and depression as well as the lower levels of satisfaction with life in the last 50 years to the "insidious takeover by schools of children's lives" (p. 8).

Based on the above, Gray judges the present education system to be harmful for children, and proposes that a way of education, rooted in biological basis for optimal learning, needs to replace the modern schooling system. Alternative ways of schooling based on the principal values of children's autonomy and cooperation, such as the Sudbury school, Montessori, Dewey, and Piaget schools prove that even in the industrialized society, the huntergatherer model of education can succeed. He suggests that these alternative schools are successful because they are modeled after the natural human educative instinct (Chapter 6) that encourage a playful, non-competitive state of mind (Chapter 7), and lead to sound social and emotional development of students (Chapter 8).

This book is likely to persuade readers to question the traditional educational system. The evidence in decline of mental health among youth (though correlational) provides a compelling need to reconsider the current education system and the success of alternative models of schooling (Chapter 5), unschooling, and parenting (Chapter 10) suggest viable alternatives to the same. A more detailed and nuanced discussion on the benefits of the current education system as well as the real challenges of reforming the system would have strengthened the book. But in spite of that weakness, all in all, this is bound to be a provocative and enjoyable read.

\section{Acknowledgements}

In the course of writing of this article, I was supported by the National Evolutionary Synthesis Center (NESCent), NSF \#EF-0905606. 